\title{
A Real-Time Harmonic Detection Method for Single-Phase Active Power Filters
}

\section{Emre Ozer*1}

\begin{abstract}
Harmonics, due to the increasing use of nonlinear loads, such as converters and solid state switching devices, has become a serious problem in power systems. Active power filters (APFs) have been used effectively to eliminate harmonic components. Precision of harmonic detection is one of the most important factors of APFs. This paper describes a novel circuit is proposed for real-time harmonic detection as an alternative to conventional approaches. This circuit is based on a switched capacitor band-pass filter and a Phase Locked Loop (PLL) which has low distortion sine wave output. This PLL follows not only phase of reference signal but also its amplitude. Harmonic components have been obtained by subtracting produced fundamental component with PLL from distorted signal. Fundamental and harmonic components of distorted line voltage and current have been successfully separated during experiments.
\end{abstract}

Keywords: Power Quality, Active Harmonic Filters, Harmonic Detection, Phase Locked Loop, Switched Capacitor Filter.

\section{Introduction}

The increasing application of power electronic devices has led to serious concerns about harmonic pollution. The compensation for harmonics and reactive currents becomes increasingly important both for power utilities and the sensitive equipment they feed with quality power, thereby avoiding fault and power loss.

The current method for harmonic cancelling by APF has been proposed at the beginning of the 1970s [1-3]. APFs basically operate by detecting the harmonics and injecting these harmonics with the same magnitude but the opposite phase into the power system. The performance of an APF depends on the inverter characteristics, control strategy, and the accuracy of the reference signal. Obviously, fast and precise harmonic detection is one of the key factors to design APFs.

Having proposed the APF technique, a number of papers have been published to introduce different methods for obtaining the APF reference current. These methods operate effectively in the frequency or time domain [4-28]. Such classification is given in Table I.

Table I: Classification of the most used harmonic detection methods

\begin{tabular}{|l|l|}
\hline Domain & Harmonic Detection Method \\
\hline Frequency Domain & Fourier Transform \\
\hline \multirow{3}{*}{ Time Domain } & Synchronous Detection Theorem \\
\cline { 2 - 2 } & Synchronous Reference-Frame Theorem \\
\cline { 2 - 2 } & Instantaneous power "pq-theory" and variants \\
\cline { 2 - 2 } & Sine-Multiplication Theorem \\
\hline
\end{tabular}

Harmonic detection by using Fourier transformation needs more than one cycle of input signal and also needs time for determination in the coming cycles. Therefore, the harmonic cancellation is delayed. Instantaneous p-q theory can only determine the harmonic current components for three phase systems and requires balanced load conditions.

All harmonic detection methods mentioned above have their own advantages and drawbacks. They are effective solutions, but all methods need a lot of time for the required determination, which usually is implemented with digital signal processor, hence the cost of the control system is too high.

This paper presents a new method to improve the performance of harmonic detection. The proposed circuit is implemented by using a switched capacitor band-pass filter and a PLL which has low distortion sine wave output to obtain harmonic components from a distorted waveform. As the experimental results show, this circuit enables the harmonic detection with high precision and speed. Therefore the harmonic detection by using PLL is suitable to improve the compensation performance of APFs

\section{Harmonic Detection by Using PLL}

The proposed method basically works by producing fundamental component and subtracting this fundamental component from distorted wave.

A PLL with low distortion sine wave output has been designed for producing fundamental component of distorted signal. This PLL follows not only phase but also amplitude of input signal. Figure1 depicts the block diagram of circuit where $u_{1}$ and $u_{h}$ are effective value of fundamental and total harmonics. $\alpha$ and $\beta$ can be unequal.

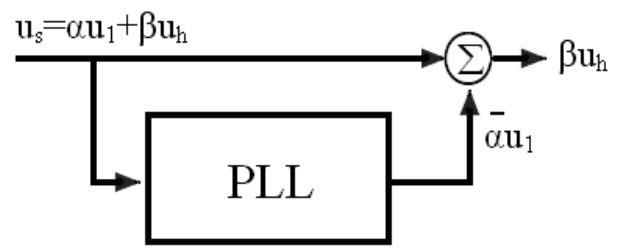

Figure-1: Block diagram 


\section{A New PLL}

A voltage controlled digital oscillator (VCDO) has been designed by using direct look-up table method for low distortion output PLL. The direct look-up table method is based on reading the stored samples of the sine waveform from a table $[29,30]$. The frequency of generated sine wave depends on the sampling interval $t(s)$, the step size $\Delta$ and the table length $\mathrm{N}$. It can be determined by

$f_{0}=\frac{\Delta}{N} f_{C L K}$

where $f_{C L K}$ means clock frequency. For producing low distortion sine wave, step size $\Delta$ should be chosen $\Delta=1$ [31-36].

The generated sampled waveform is only an approximation to sine wave. Because of the approximations made in the sine wave generation, a certain amount of the energy of signals falls into other frequencies. This spurious energy is called harmonic distortion [37]. It is defined as below.

$d=\frac{\sqrt{U_{2 f_{1}}^{2}+U_{3 f_{1}}^{2}+U_{4 f_{1}}^{2}+\cdots}}{U_{t o t}}$

$U_{n f_{1}}$ is effective value of $\mathrm{n}$. order harmonic and $U_{\text {tot }}$ is effective value of total signals. In this study, harmonic distortion is measured by using Hameg HM 8027 distortion meter [38].

The designed VCDO is shown in Figure-2 and was performed by using a microcontroller 16F84A [39]. The length of the look-up table is $\mathrm{N}=256$. Analog signal was generated by using a digital to analog converter DAC0808 [40]. The required clock is produced by using a voltage controlled oscillator. So we can adjust the frequency of sine wave by a control voltage. Figure- 3 shows the transfer function of VCDO.

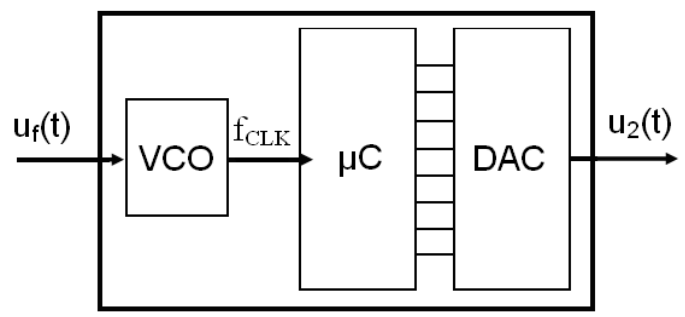

Figure-2: Block diagram of VCDO

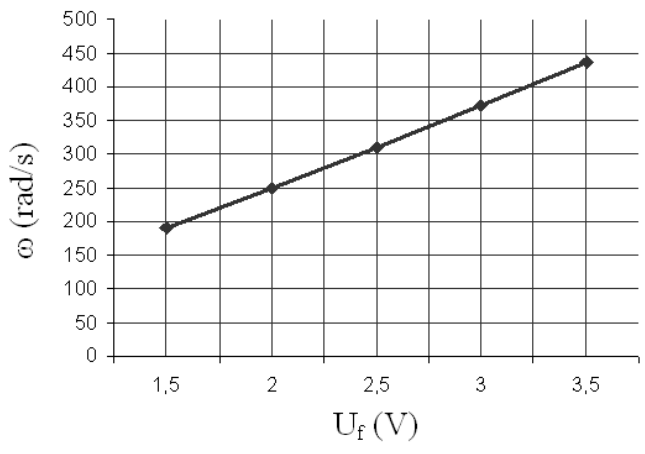

Figure-3: Transfer function of the VCDO

$\omega$ is frequency of the VCDO, $U_{f}$ is control voltage and $K_{0} \cong$ $123 \mathrm{rad} / \mathrm{sV}$ is the VCDO gain. The distortion factor of produced sine wave is measured $d=\% 0.03$. The PLL used this VCDO is shown in Figure-4.

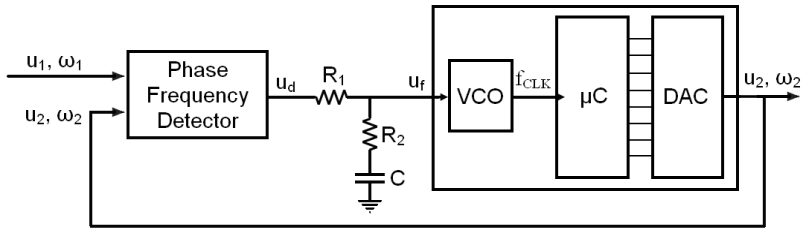

Figure-4: Block diagram of a PLL

This PLL consists of Phase-Frequency Detector (PFD), a Loop Filter (LF) and VCDO. The natural frequency $\omega_{n}$ and damping factor $\zeta$ have an important influence on the dynamic performance of the PLL. In order to keep up with reference signal changes they must be optimum. The example below is designed according to the following conditions:

Line frequency $45-55 \mathrm{~Hz}$, settling time $1 \mathrm{~s}$, overshoot $<20 \%$ The phase-transfer function of PLL which is given in Figure-5 [41].

$H(s) \cong \frac{2 s \zeta \omega_{n}+\omega_{n}^{2}}{s^{2}+2 s \zeta \omega_{n}+\omega_{n}^{2}}$

natural frequency $\omega_{n}=\sqrt{\frac{K_{0} K_{d}}{\tau_{1}+\tau_{2}}}$, damping factor $\zeta=\frac{\omega_{n}}{2}\left(\tau_{2}+\frac{1}{K_{0} K_{d}}\right)$

time constants $\tau_{1}=R_{1} C, \tau_{2}=R_{2} C$

the phase-frequency detector gain $K_{d}=0.4 \mathrm{~V} / \mathrm{rad}$

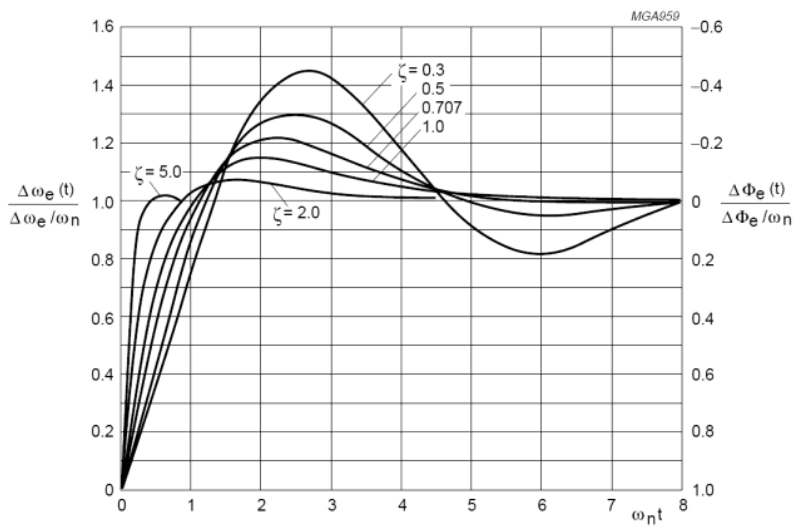

Figure-5: Frequency step response of type 2, second order PLL [42]

From Figure- 5 it can be seen that the damping factor $\zeta=0.8$ that will produce an overshoot of less than $20 \%$ and settle to within $5 \%$ at $\omega_{n} t=4.5$. The required settling time is $1 \mathrm{~s}$. Then, time constants can be calculated.

$\tau_{2} \cong 0.34 s$

$\tau_{1} \cong 2.1 \mathrm{~s}$

$C=100 \mu F$ if chosen

$R_{1} \cong 21 k \Omega$

$R_{2} \cong 3.4 k \Omega$

A circuit shown in Figure-6 is designed for PLL which follows the amplitude of the reference signal. The reference signal $u_{s}$ is taken from the power net by a voltage divider. $\alpha$ the divider ratio for fundamental and $\beta$ is for the harmonics which has not to be equal to $\alpha$. 


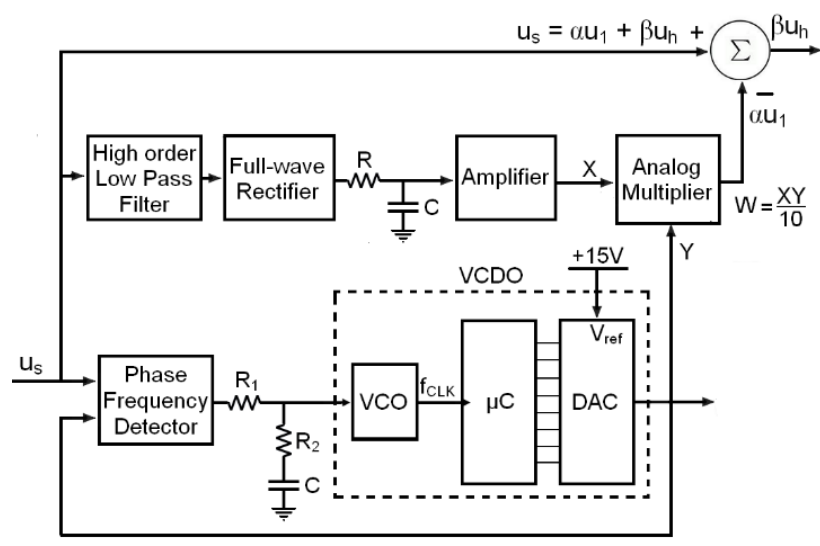

Figure-6: A new PLL that can follow amplitude of the reference signal

Reference voltage of digital to analog converter is chosen $15 \mathrm{~V}$ for producing a sine wave that has constant amplitude. Input signal is filtered by a $8^{\text {th }}$ order low pass filter to obtain fundamental component. Then, this fundamental component is rectified. So, we obtain a dc voltage proportional to the amplitude of the fundamental component. This dc voltage and sine wave are applied to the analog multiplier. Output of the amplifier is set to $\alpha u_{1}$ and therefore this PLL is able to follow the amplitude of the reference signal. Owing to this feature the fundamental is eliminated totally at the output of summing amplifier. Distortion factor of sine wave remains at the same level, $d=\% 0.03$. The time constant of RC low pass filer is crucial. As it has a strong influence on the PLL system it must be optimized.

\section{Effects Of Harmonics Phase and Solution}

Due to the fact that harmonics are not in same phase, fundamental component of distorted wave and produced sine wave by PLL have different phases. Phase detector is a logic circuit. Therefore, it senses the zero-cross of distorted signal. As a result, we can't produce fundamental component of distorted signal in phase. A new circuit is proposed for solving this problem. Block diagram of the circuit is shown in Figure-7.
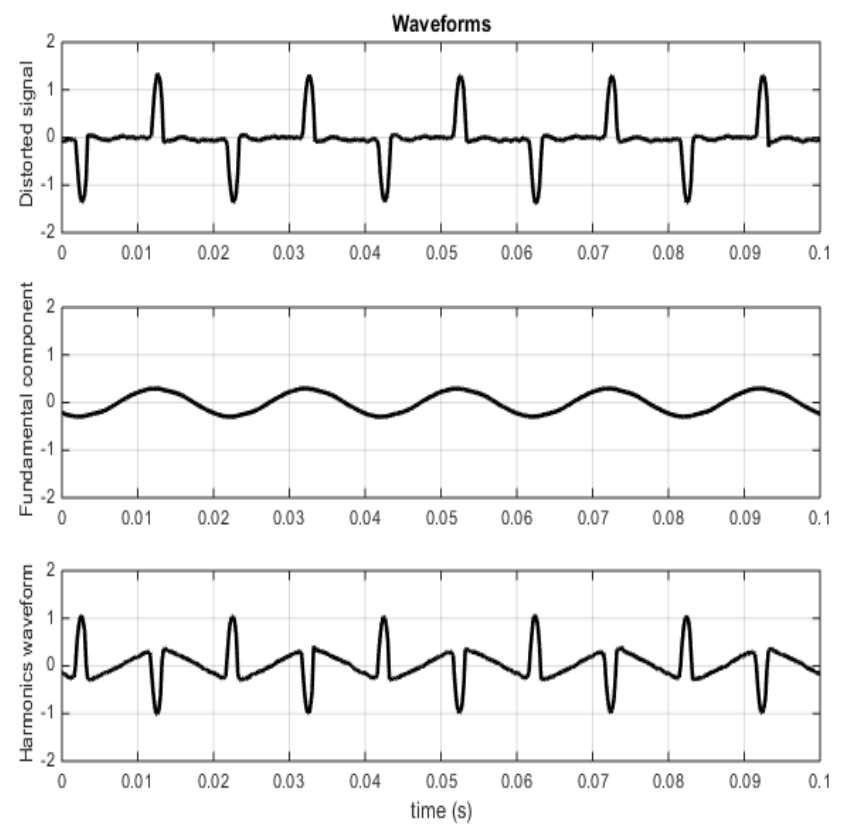

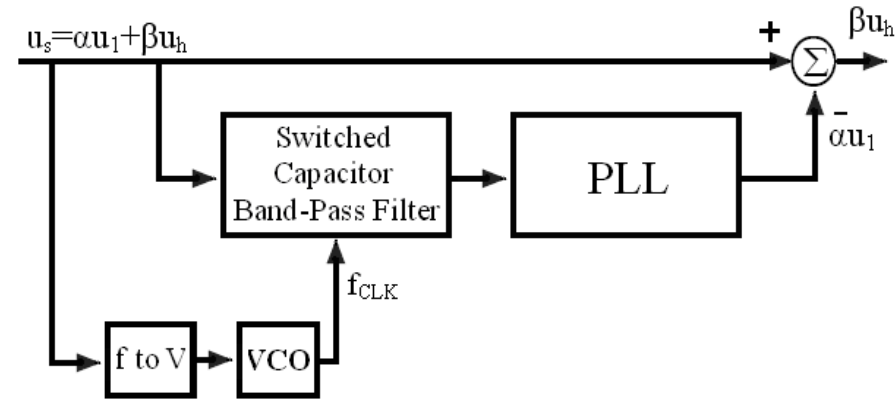

Figure-7: Block diagram of the proposed PLL which is locked to the phase of the fundamental components

A switched-capacitor filter is used as band-pass. Its cutoff frequencies are set to a typical accuracy of $\pm 0.2 \%$ by an external clock frequency. The center frequency of band pass filter equals to the line frequency and gain is 1 in the filter's pass band. So the fundamental is passed without changing phase and magnitude, but the harmonics are suppressed.

Another potential problem in the power systems is the drift of the line frequency. When its frequency is changed, the switchedcapacitor filter's center frequency must also be tracked. The center frequency of a switched-capacitor filter is a certain fraction of the frequency of a square-wave clock. This allows filter designs whose cutoff frequencies are variable over a wide range simply by changing the clock frequency [43]. In order to solve unstable line frequency problem, a new clock generator circuit was developed by using this feature. The suggested clock generator circuit is shown in Figure-7.

The clock generator circuit consists of two basic functional blocks: A frequency to voltage converter and a voltage-controlled oscillator (VCO). Frequency to voltage converter produces a dc voltage proportional to the line frequency. The VCO oscillates at an angular frequency, which is determined by the output signal of the frequency to voltage converter. This circuit looks like a frequency multiplier. The required clock frequency obtained by multiplying line frequency with a constant.
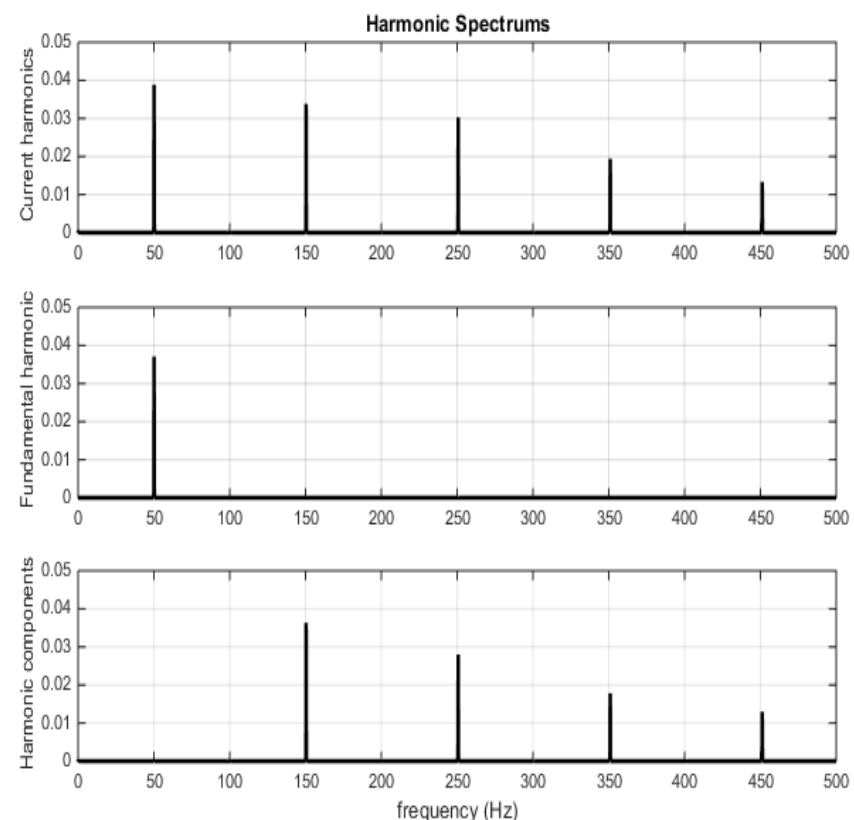

Figure-8: Waveforms and harmonic spectrums 


\section{Experimental Results}

Figure-7 shows the experimental set-up for testing the proposed method. The filter, a MAX267, is a commercially available switched-capacitor, consisting of two second-order filters. It needs $\pm 5 \mathrm{~V}$ power supplies. An input clock and 5-bit programming input precisely set the filter clock/center frequency ratio. Quality factor $\mathrm{Q}$ is also programmable from 0.5 to 64 . The MAX267 operates with center frequency up to $57 \mathrm{kHz}$ by employing lower $\frac{f_{C L K}}{f_{0}}$ ratios. Waveform and spectral measurements were made with Data Acquisition Hardware and LabVIEW software [44]. Figure-8 shows the waveform of a computer power supply current and its harmonics derived from designed circuit. Distortion factor, as measured with an HM 8027 distortion meter, is $d=\% 0.03$.

\section{CONCLUSION}

In this study, a real-time harmonic detection method for single phase active power filters has been presented. The proposed method basically works by producing fundamental component of distorted wave and subtracting this fundamental component from distorted wave. This method uses a PLL and a switched capacitor bandpass filter. The switched capacitor band-pass filter is used for sensing correct the phase of the fundamental component. Its center frequency is set at the line frequency, and gain is 1 in pass band. A clock generator circuit is designed for tracking the line frequency. So, the harmonics are suppressed but the fundamental is passed without changing phase and magnitude. The PLL is used for producing fundamental component of distorted wave. The fundamental component of a distorted signal with $0.03 \%$ total harmonic distortion was generated by using direct look-up table method. As the experimental results shown in Figure-8, this circuit enables the harmonic detection with high precision and speed.

\section{References}

[1] Bird B. M., Marsh J. F., and McLellan P. R. "Harmonic reduction in multiplex convertors by triple-frequency current injection," in Proc. of the Institution of IET Electrical Engineers, 1969, pp. 1730-1734.

[2] Sasaki H., Machida T. "A New Method to Eliminate AC Harmonic Currents by Magnetic Flux CompensationConsiderations on Basic Design," IEEE Trans. on Power Apparatus and Systems, vol. PAS-90, 1971, pp. 2009-2019.

[3] Ametani A. "Harmonic reduction in thyristor converters by harmonic current injection," IEEE Trans. on Power Apparatus and Systems, 1976, vol. 95, pp. 441-449.

[4] El-Habrouk, M., Darwish, M. K., and Mehta, P. "Active Power Filters: A Review" Proc. IEE Electric Power Applications, 2000, 147(5): 403-413.

[5] Jou, H. L. and Wu, H. -Y. "New Single-Phase Active Power Filter" Proc. IEE Electric Power Applications, 1994, 141(3): 129-134.

[6] Hsu, C. Y. and Wu, H. -Y. "A New Single-Phase Active Power Filter with Reduced Energy-Storage Capacity" Proc. IEE Electric Power Applications, 1996. 143(1): 25-30.

[7] Jeong, S. G. and Woo, M. H. "DSP-Based Active Power Filter with Predictive Current Control" IEEE Trans. on Industrial Electronics, 1997, 44(3): 329-336.

[8] Buso, S. Malesani, L., Mattavelli, P., and Veronese, R. "Design and Fully Digital Control of Parallel Active Power Filters for Thyristor Rectifiers to Comply with IEC-1000-32 Standards" IEEE Trans. on Industry Applications, 1998, 34(3): 508-517.

[9] Jintakosonwit, P., Fujita, H., and Akagi, H. "Control and Performance of a Fully-Digital-Controlled Shunt Active
Filter for Installation on Power Distribution System" IEEE Trans. on Power Electronics, 2002, 17(1): 132- 140.

[10] Fukuda, S. and Endoh, T. "Control Method for a Combined Active Filter System Employing a Current Source Converter and a High Pass Filter" IEEE Trans. on Industry Applications, 1995, 31(3): 590-597.

[11] Khositkasame, S. and Sangwongwanich, S. "Design of Harmonic Current Detector and Stability Analysis of a Hybrid Parallel Active Filter" Proc. of the Power Conversion Conference (PCC), 1997, Japan, pp. 181-186.

[12] Routimo, M., Salo, M., and Tuusa, H. "A Novel Control Method for Wideband Harmonic Compensation" Proc. of the IEEE International Conference on Power Electronics and Drive Systems (PEDS), 2003, Singapore, pp. 799-804.

[13] Singh, B., Al-Haddad, K., and Chandra, A. "A Review of Active Filters for Power Quality Improvement" IEEE Trans. on Industrial Electronics, 1999, 46(5): 960-971.

[14] Wu, J. -C. and Jou, H. -L. "Simplified Control Method for the Single-Phase Active Power Filter" Proc. IEE Electric Power Applications, 1996, 143(3): 219-224.

[15] Rigby, B. S. and Harley, R. G. "The Design and Control of an Inverter-Based Series Compensator for Dynamic Performance" Proc. of the IEEE Power Engineering Society Summer Meeting, 1999, Canada, pp. 1146-1151.

[16] Bhattacharya, S. and Divan, D. "Design and Implementation of a Hybrid Series Active Filter System" Proc. of the IEEE Power Electronics Specialists Conference (PESC), 1995, USA, pp. 189-195.

[17] Bhattacharya, S. and Divan, D. "Synchronous Frame Based Controller Implementation for a Hybrid Series Active Filter System" Proc. of the IEEE Industry Applications Conference, 1995, USA, pp. 2531-2540.

[18] Peng, F. Z., Akagi, H., and Nabae, A. “A New Approach to Harmonic Compensation in Power Systems - a Combined System of Shunt Passive and Series Active Filters" IEEE Trans. on Industry Applications, 1990, 26(6): 983-990.

[19] Sung, N. G., Lee, J. D., Kim, B. T., Park, M., and Yu, I. K. "Novel Concept of a PV Power Generation System Adding the Function of Shunt Active Filter" Proc. of the IEEE Transmission and Distribution Conference, 2002, Japan, pp. 1658-1663.

[20] El-Habrouk, M., Darwish, M. K., and Mehta, P. “A Survey of Active Filters and Reactive Power Compensation Techniques" Proc. of the IEE International Conference on Power Electronics and Variable Speed Drives, 2000, London, UK, pp. 7-12.

[21] Grady, W. M., Samotyj, M. J., and Noyola, A. H. "Survey of Active Power Line Conditioning Methodologies" IEEE Trans. on Power Delivery. 1990. 5(3): 1536-1542.

[22] Norman, M., Ahsanul, A., Senan, M., and Hashim, H. "Review of Control Strategies for Power Quality Conditioners" Proc. of the IEEE National Conference on Power and Energy Conference (PECon), 2004, Malaysia, pp. 109-115.

[23] Chen, D. -H. and Xie, S. -J. "Review of Control Strategies Applied to Active Power Filters" Proc. of the IEEE International Conference on Electric Utility Deregulation, Restructuring and Power Technologies (DRPT), 2004, Hong Kong, pp. 666-670.

[24] Akagi, H., Kanazawa, Y., and Nabae, A. "Instantaneous Reactive Power Compensators Comprising of Switching Devices without Energy Storage Components" IEEE Trans. on Industry Applications, 1984, 20(3): 625-630. 
[25] Leow, P. L. and Naziha, A. A. "SVM Based Hysteresis Current Controller for a Three Phase Active Power Filter" Proc. of the IEEE National Conference on Power and Energy Conference (PECon), Nov. 29-30, 2004, Malaysia, pp. 132136.

[26] Jou, H. -L. "Performance Comparison of the Three-Phase Active-Power-Filter Algorithms" Proc. IEE Generation, Transmission and Distribution, 1995, 142(6): 646-652.

[27] Wu, T. -F., Shen, C. -L., Chiu, J. -Y., and Chen, C. -C. “An APF with MAPPT Scheme to Improve Power Quality, Proc. of the IEEE International Conference on Electrical and Electronic Technology, August 19-22, 2001, Singapore, pp. 620-626.

[28] Chen, C. L., Chen, E. L., and Huang, C. L. "An Active Filter for Unbalanced Three-Phase System using Synchronous Detection Method" Proc. of the Power Electronics Specialist Conference (PESC), June 20-25, 1994, Taipei, Taiwan, pp. 1451-1455.

[29] D. Garcia, "Precision digital sine wave generation with the TMS32010," In Digital Signal Processing Applications with the TMS320 Family (Texas Instruments), 1989.

[30] V. Matic, V. Marinkovic-Nedelicki and V. Tadic, "Comparison of digital signal processing methods for sine wave signal generation," in Proc. SBT/IEEE International Telecommunications Symposium, 1998, vol. 1, pp. 290 295.

[31] Y. C. Jenq, "Digital spectra of nonuniformly sampled signals. II. Digital look-up tunable sinusoidal oscillators," IEEE Trans. On Instrumentation and Measurement, September 1988, vol. 37, pp. 358-362.

[32] Y. C. Jenq, "Digital spectra of nonuniformly sampled signals: fundamentals and high-speed waveform digitizers," IEEE Trans. on Instrumentation and Measurement, June 1988, vol. 37, pp. 245-251.

[33] M. M. Al-Ibrahim, S. Bataineh, "High resolution and low distortion digital look-up-table sinusoidal oscillators," International Journal of Electronics, January 2000, vol. 87, pp. 33-41.

[34] M. Schanerberger, S. S. Awad, "The implementation of a digital sine wave oscillator using the TMS320C25: distortion reduction and applications," IEEE Trans. on Instrumentation and Measurement, December 1990, vol. 39, pp. 870-873.

[35] J. Tierney, C. Rader, and B. Gold, "A digital frequency synthesizer," IEEE Trans. on Audio and Electroacoustics, March 1971, vol. 19, pp. 48-57.

[36] T. Abeyasekera, C. M. Johnson, D. J. Atkinson, and M. Armstrong, "Elimination of subharmonics in direct look-up table (DLT) sine wave reference generators for low-cost microprocessor-controlled inverters," IEEE Trans. on Power Electronics, 2003, vol. 18, pp. 1315-1321.

[37] IEEE Recommended Practices and Requirements for Harmonic Control in Electrical Power Systems, IEEE Std. $519,1992$.

[38] HM 8027 Distortion Meter, Hameg Insruments, Data Sheet, Germany, 1995.

[39] PIC 16F84A 8-bit Microcontroller, Microchip Technology Inc., Data Sheet, USA, 2001.

[40] DAC0808 8-Bit D/A Converter, National Semiconductor Corporation, Data Sheet, USA, 1999.

[41] R. E. Best, 2007, Phase Locked Loops. USA: McGraw-Hill Professional, 2003.

[42] CD74HC4046A Phase Locked Loop, Texas Instruments, Data Sheet, USA, 2003.
[43] MAX267 Pin-Programmable Universal and Bandpass Filters, Maxim Integrated Products, Inc., Data Sheet, USA, 2015.

[44] NI LabVIEW 2009 for Acquiring Data and Processing Signals, National Semiconductor Corporation, USA. 